\title{
The direct and indirect costs of adult atopic dermatitis
}

\author{
Janna Manjelievskaia, PhD; Natalie Boytsov, PhD; Matthew A Brouillette; Uchenna Onyekwere, MD; \\ Evangeline Pierce, PhD; Orin Goldblum, MD; and Machaon Bonafede, PhD
}

\section{What is already known about this subject}

- Most analysis of the economic burden of atopic dermatitis has focused on the pediatric population; however, the condition persists into adulthood for many patients, a population with limited recent published data following the availability of newer therapies, such as dupilumab.

\section{What this study adds}

- The economic burden of atopic dermatitis in adults may manifest by increased health care expenditures, including drug costs and increased short-term disability costs.

\section{ABSTRACT}

BACKGROUND: Atopic dermatitis is considered a childhood illness, and the direct and indirect health care burden of atopic dermatitis in adults is not fully understood.

OBJECTIVE: To measure the direct and indirect costs of atopic dermatitis among adults in 2018.

METHODS: This retrospective cohort study compared commercial and Medicare-insured adults with atopic dermatitis in 2018 with directly matched (1:3) adults without atopic dermatitis. Atopic dermatitis prevalence was reported. Health care utilization, direct health care costs, and work loss data were compared between cohorts. This analysis was repeated for adults with atopic dermatitis in 2016 and 2017

RESULTS: 31,164 adults with atopic dermatitis in 2018 were identified and directly matched (1:3) to controls. Adults with atopic dermatitis had greater utilization of outpatient services, outpatient pharmacy services, and short-term disability benefits than controls. Unadjusted annual health care costs in 2018 were $\$ 4,979$ higher for adults with atopic
J Manag Care Spec Pharm. 2021;27(10):1416-25

Copyright $\odot 2021$, Academy of Managed Care Pharmacy. All rights reserved.

dermatitis $(\$ 14,603)$ than for the matched controls $(\$ 9,624)$, driven by outpatient services and pharmacy. Findings were supported by analyses of adults from 2016 and 2017 and multivariable analyses. One limitation of this study was that patients with mild cases of atopic dermatitis may not seek medical treatment and may be underrepresented in the study cohort.

CONCLUSIONS: The direct health care and indirect (short-term disability) health care costs of atopic dermatitis present a significant health care burden among the adult population.
Atopic dermatitis is a chronic inflammatory skin condition characterized by pruritis and eczematous lesions. ${ }^{1}$ Traditionally considered a childhood illness, atopic dermatitis can persist into or develop de novo in adulthood. ${ }^{2}$
In a survey of US adults, $10.2 \%$ reported experiencing atopic dermatitis in the previous year, while $3.2 \%$ reported atopic dermatitis in combination with a history of asthma or hay fever. ${ }^{3}$
Generally considered a mild disease, atopic dermatitis is associated with a substantial medical, productivity, and quality of life burden. ${ }^{4-8}$ Adults with atopic dermatitis report more physician office visits, emergency 
department visits, lost workdays, and lower vitality, social functioning, and mental health scores compared with the general population. ${ }^{5-7}$ In 2006, the economic burden of atopic dermatitis in the United States was estimated to be \$1.6 billion, of which $\$ 1.0$ billion were attributed to direct health care costs, and $\$ 600$ million were attributed to lost productivity. ${ }^{9}$ Although hospitalizations are rare, an estimated 20,705 adults were admitted to the hospital between 2002 and 2012 with a primary diagnosis of atopic dermatitis or eczema, costing an estimated $\$ 8.3$ million annually. ${ }^{10}$ The US standard of care for atopic dermatitis during the study period primarily involved topical treatments and systemic therapies (such as phototherapy or systemic immunosuppressants for patients whose condition was not controlled with topical therapies alone). ${ }^{11}$

The objective of this study was to provide an updated estimate of the economic burden of atopic dermatitis by comparing health care resource utilization, direct costs, and indirect costs due to work loss in 2018 among patients with atopic dermatitis with controls without atopic dermatitis. Prevalence of atopic dermatitis in the study databases was assessed. Additional selection criteria were applied to the study population used in the analysis. Multivariable analysis was used to control for baseline characteristics and evidence of atopic dermatitis before 2018. The analysis was repeated for adults with atopic dermatitis in 2016 or 2017.

\section{Methods}

\section{DATA SOURCE}

This retrospective study used US data spanning the study period (January 1, 2014-December 31, 2018, the earliest of which included the 24-month baseline period for the 2016 study cohort) from 4 IBM MarketScan databases: the Commercial Claims and Encounters Database, the Medicare Supplemental and Coordination of Benefits Database, the Health and Productivity Management Database, and the Weather Database. The Commercial Claims and Medicare databases capture longitudinal administrative claims data over the continuum of care for commercially insured working-age adults and their dependents, as well as for individuals with Medicare supplemental insurance paid for by employers. The Health and Productivity Management Database contains workplace absence, short-term disability, and workers' compensation linked to health care claims data for a subset of IBM employer clients that contribute data to the Commercial Claims Database. The Weather Database links metropolitan statistical area-specific daily weather data, including temperature, humidity, barometric pressure, air quality, and particulate matter concentration, to patients' metropolitan statistical area information and administrative claims. Weather data were available for the 2016 and 2017 study years only.

All database records were statistically deidentified and certified to be fully compliant with US patient confidentiality requirements set forth in the Health Insurance Portability and Accountability Act of 1996. Because this study used only deidentified patient records and did not involve the collection, use, or transmittal of individually identifiable data, this study was exempted from institutional review board approval.

\section{PATIENT SELECTION AND MATCHING}

The primary analysis examined adult patients (aged $\geq 18$ years) with a diagnosis of atopic dermatitis ( $\geq 1$ inpatient or 2 nondiagnostic outpatient medical claims from any provider, $\geq 30$ days apart, or 1 outpatient claim from a dermatologist, allergist, or immunologist with an International Classification of Diseases, Tenth Revision, Clinical Modification diagnosis code for atopic dermatitis [L20.0, L20.9, L20.81, L20.89]) between January 1, 2018, and December 31, 2018. The index date was the date of the first atopic dermatitis claim in 2018. Patients were directly matched on age, sex, and geographic region (based on patient's state of residence) at a ratio of 1:3 to controls without a diagnosis of atopic dermatitis or eczema anytime during the study period. Adults with atopic dermatitis and their direct matched controls must have had continuous enrollment with medical and pharmacy benefits for the entire 2018 calendar year (observation year) and 24 months preceding the index date (baseline period).

All analyses were repeated for adults with an atopic dermatitis diagnosis in the 2017 and 2016 calendar years and their matched controls.

\section{PATIENT CHARACTERISTICS}

Baseline demographic characteristics were measured on index date and included age, sex, geographic region, and payer (commercial or Medicare). Baseline clinical characteristics measured during the baseline period included the Deyo-Charlson Comorbidity Index (DCI) scores and comorbid conditions (allergies, anxiety, asthma, cardiovascular disease, depression, pain, pruritus, skin infections, and sleep disorders). ${ }^{12}$ Patients with an additional atopic dermatitis diagnosis during the baseline period were categorized as prevalent, whereas patients without an atopic dermatitis diagnosis in the baseline period were considered incident.

\section{OUTCOMES}

All-cause and atopic dermatitis-related health care resource utilization, including inpatient admissions, length 
of stay, emergency department visits, outpatient services, and outpatient pharmacy fills, were reported for each cohort during the observation year. Unadjusted all-cause and atopic dermatitis-related annual costs for inpatient services, outpatient services, and outpatient pharmacy services were calculated for the observation year. Atopic dermatitis-related claims were defined as medical claims with a diagnosis of atopic dermatitis in any position and outpatient pharmacy claims for treatments that may be used to treat atopic dermatitis and are listed in Supplementary Table 1 (available in online article). Systemic treatments were selected by overall medication class specifically: oral corticosteroids, antibiotics, antihistamines, antivirals, biologics, and immunosuppressants.

Direct costs were the paid amounts of fully adjudicated claims, including insurer payments, as well as patient cost sharing in the form of copayment, deductible, and coinsurance. Annual costs for the 2016 and 2017 cohorts were adjusted to 2018 US dollars using the medical care component of the Consumer Price Index..$^{13}$

Indirect costs from workplace absence, short-term disability, and workers' compensation were assessed for the subset of patients in each cohort whose employers provided these benefits and contributed to the Health and Productivity Management Database. Indirect costs were calculated based on the Bureau of Labor Statistics estimated, seasonally adjusted, hourly wage of all employees on private nonfarm payrolls in the year of interest. Indirect costs of short-term disability were adjusted to $70 \%$ of the daily wage to reflect that the short-term disability programs only pay out a portion of employees' wages. ${ }^{14}$ Workers' compensation costs were captured directly from the submitted claims.

\section{PREVALENCE}

The prevalence of atopic dermatitis in adults was reported for 2016, 2017, and 2018 calendar years. Prevalence was measured by calculating the percentage of patients aged 18 or more years with a diagnosis of atopic dermatitis during the observation year among all patients in the same calendar year with the same enrollment criteria during the observation year. A sensitivity analysis was performed by including patients with all L20.X diagnosis codes during the observation year, which included diagnoses for allergic and childhood eczema.

\section{STATISTICAL ANALYSIS}

Means and SDs were reported for continuous variables, and statistical significance was determined using Student's t-tests. Frequencies and percentages were reported for categorical variables, and statistical significance was determined using chi-square tests. The alpha level for all statistical tests was 0.05. All data analyses were conducted using WPS Analytics version 4.1 (World Programming).

Multivariable-adjusted total all-cause health care costs and total all-cause prescription cost estimates were modeled using generalized linear models with a log link and gamma error distribution for each annual cohort. Only 2 patients in the atopic dermatitis cohort had $\$ 0$ of total allcause health care costs, so we were unable to fit a logistic regression model predicting probability of any costs. A two-part model was fit for the outcome of total all-cause prescription costs.

Cost estimates were generated by recycled prediction, which provides covariate-adjusted estimates of cost. ${ }^{15}$ The main explanatory item of interest was the presence of prevalent atopic dermatitis, incident atopic dermatitis, or no atopic dermatitis. Each model adjusted for age, sex, geographic region, DCI, any allergy, asthma, eczema, skin infection, pain, pruritus, sleep disorder, cancer, cardiovascular disease, depression, diabetes, number of distinct medications, and use of outpatient phototherapy, which was adjusted because of the low use in this study. The total cost models also adjusted for the number of outpatient prescriptions for systemic and topical atopic dermatitis medications. The 2016 and 2017 models also adjusted for weather variables, including pollen index, average temperature, and average humidity.

\section{Results}

\section{ATOPIC DERMATITIS PREVALENCE}

The prevalence of atopic dermatitis among individuals aged over 18 years in the MarketScan Commercial and Medicare databases was $0.30 \%$ in $2016,0.30 \%$ in 2017 , and $0.33 \%$ in 2018. The prevalence of all L20 codes among adults in the MarketScan Commercial and Medicare databases was $0.36 \%$ in $2016,0.44 \%$ in 2017 , and $0.55 \%$ in 2018 .

\section{MAIN ANALYSIS: ADULT PATIENTS WITH ATOPIC DERMATITIS DIAGNOSIS IN 2018}

Overall, 31,164 adult patients with a diagnosis of atopic dermatitis were selected for the primary analyses (Figure 1). The average age of these patients was 45.3 years, and $64.3 \%$ were female (Table 1). Compared with matched controls, adults with atopic dermatitis had a higher frequency of comorbidities, including a greater percentage of patients with any allergies such as allergic rhinitis or food allergies (37.3\% vs $15.0 \%, \mathrm{P}<0.001)$ or asthma $(17.2 \%$ vs $7.5 \%, \mathrm{P}<0.001)$ during the baseline period. Of the comorbidities assessed, atopic dermatitis patients also had higher frequencies of 


\section{FIGURE 1 Patient Selection}

Patients with $\geq 1$ inpatient claim, $\geq 2$ outpatient claims from any provider ( $\geq 30$ days apart), or $\geq 1$ outpatient claim from a dermatologist, allergist or immunologist with a diagnosis of $A D$ between January $1,201 X^{a}$ and December $31,201 X$. The date of the first claim in $201 X$ is the index date

2018 AD cohort, $\mathrm{n}=116,541(100 \%)$ 2017 AD cohort, $n=108,859(100 \%)$ 2016 AD cohort, $n=116,959(100 \%)$
Patient without evidence of $A D$ or eczema at any time between January 1, 2014, and December 31, 201X

2018 controls, $n=26,553,061(100 \%)$

2017 controls, $\mathrm{n}=25,810,634(100 \%)$

2016 controls, $n=28,695,890(100 \%)$

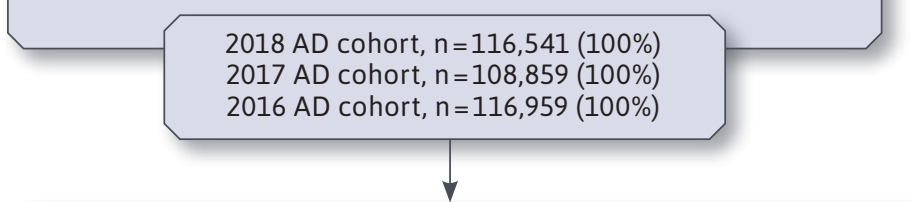

AND aged $\geq 12$ years on January $1,201 X$

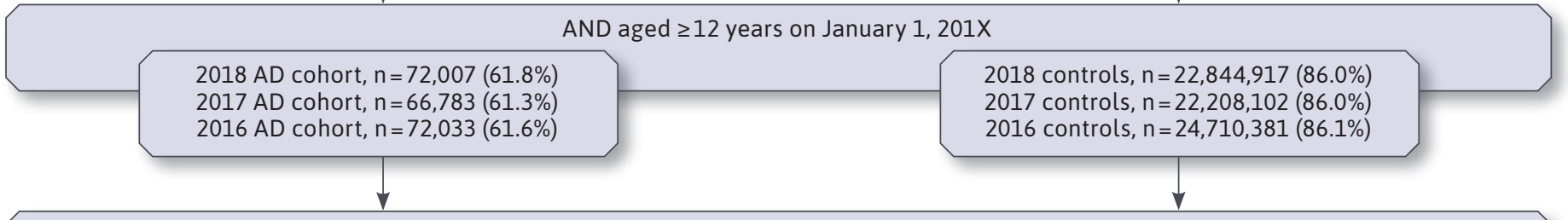

AND continuous enrollment with medical and pharmacy benefits during the entirety of $201 \mathrm{X}$ and for $\geq 24$ months before the index date

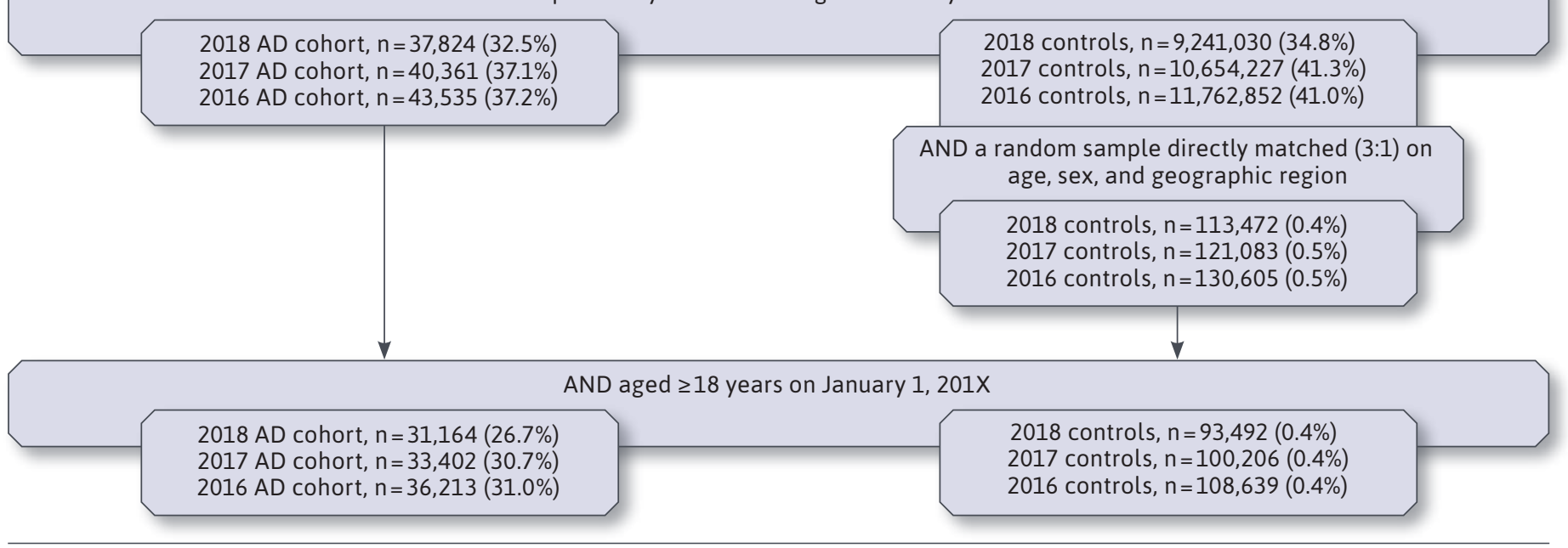

${ }^{a} X$ is a wildcard for the year specific to the cohort. $X$ is 8 for the 2018 cohorts, 7 for the 2017 cohorts, and 6 for the 2016 cohorts. $A D=$ atopic dermatitis.

cardiovascular disease (33.6\% vs $30.4 \%)$ and skin infections (33.5\% vs $17.4 \%$; all $\mathrm{P}<0.001)$, compared with their matched controls, as well as pain (64.0 \% vs $54.0 \%)$ and pruritus (12.1 $\%$ vs $2.4 \%$ ), which could be a result of the symptomology of atopic dermatitis or another condition. Patients with atopic dermatitis were also more likely to be diagnosed with anxiety (17.9\% vs $14.6 \%)$, depression (15.2\% vs $12.3 \%)$, or sleep disorders $(15.0 \%$ vs $11.4 \%$; all $\mathrm{P}<0.001)$ during the baseline period.

Compared with matched controls, adults with atopic dermatitis in 2018 had greater all-cause health care resource utilization of outpatient services and outpatient pharmacy but similar utilization of inpatient services (Table 2). Adults with atopic dermatitis had a significantly higher proportion of patients with at least 1 all-cause emergency department visit $(21.4 \%$ vs $17.6 \%, P<0.001)$, all-cause outpatient office visit $(99.9 \%$ vs $84.2 \%, P<0.001)$, or outpatient prescription (97.1\% vs $81.1 \%, \mathrm{P}<0.001)$ compared with matched controls. Adults with atopic dermatitis had significantly more outpatient services per patient and significantly more overall outpatient prescriptions per patient (mean [SD]) than controls (21.3 [21.7] vs 14.0 [18.9], $\mathrm{P}<0.001)$.

Inpatient admissions and emergency department visits related to atopic dermatitis were rare among patients with 


\begin{tabular}{|c|c|c|c|c|}
\hline \multirow[b]{2}{*}{ Age, mean years (SD) } & \multicolumn{2}{|c|}{$\begin{array}{l}2018 \text { adult AD } \\
\text { cohort }(n=31,164)\end{array}$} & \multicolumn{2}{|c|}{$\begin{array}{l}2018 \text { adult control } \\
\text { cohort }^{\mathrm{a}}(\mathrm{n}=93,492)\end{array}$} \\
\hline & 45.3 & $(16.8)$ & 45.3 & $(16.8)$ \\
\hline \multicolumn{5}{|l|}{ Sex, n (\%) } \\
\hline Female & 20,037 & $(64.3)$ & 60,111 & $(64.3)$ \\
\hline Male & 11,127 & $(35.7)$ & 33,381 & $(35.7)$ \\
\hline \multicolumn{5}{|l|}{ Geographic region, $\mathrm{n}(\%)$} \\
\hline Northeast & 9,447 & $(30.3)$ & 28,341 & $(30.3)$ \\
\hline North Central & 4,396 & $(14.1)$ & 13,188 & $(14.1)$ \\
\hline South & 12,782 & $(41.0)$ & 38,346 & $(41.0)$ \\
\hline West & 4,539 & $(14.6)$ & 13,617 & $(14.6)$ \\
\hline Medicare (vs commercial), n (\%) & 2,977 & $(9.6)$ & 8,887 & $(9.5)$ \\
\hline Deyo-Charlson Comorbidity Index, mean (SD) & 0.7 & $(1.3)$ & 0.5 & $(1.2)^{\mathrm{b}}$ \\
\hline \multicolumn{5}{|l|}{ Comorbid medical conditions, n (\%) } \\
\hline Allergies & 11,619 & $(37.3)$ & 14,006 & $(15.0)^{b}$ \\
\hline Anxiety & 5,568 & $(17.9)$ & 13,678 & $(14.6)^{\mathrm{b}}$ \\
\hline Asthma & 5,345 & $(17.2)$ & 7,010 & $(7.5)^{\mathrm{b}}$ \\
\hline Cardiovascular disease & 10,465 & $(33.6)$ & 28,441 & $(30.4)^{\mathrm{b}}$ \\
\hline Depression & 4,732 & $(15.2)$ & 11,538 & $(12.3)^{\mathrm{b}}$ \\
\hline Pain & 19,937 & $(64.0)$ & 50,511 & $(54.0)^{\mathrm{b}}$ \\
\hline Pruritus & 3,754 & $(12.1)$ & 2,233 & $(2.4)^{b}$ \\
\hline Skin infections & 10,431 & $(33.5)$ & 16,230 & $(17.4)^{b}$ \\
\hline Sleep disorders & 4,662 & $(15.0)$ & 10,690 & $(11.4)^{\mathrm{b}}$ \\
\hline Incident AD (vs prevalent) ${ }^{c}$ & 25,868 & $(83.0)$ & & \\
\hline \multicolumn{5}{|c|}{$\begin{array}{l}{ }^{a} \text { Controls were directly matched to } A D \text { patients (3:1) on age, sex, and geographic region. } \\
\text { bP }<0.001 \text {. } \\
\text { 'Patients without any claims with an } A D \text { diagnosis in the } 24 \text { months before the index date were considered } \\
\text { to have incident } A D \text {. } \\
A D=\text { atopic dermatitis; } N A=\text { not available. }\end{array}$} \\
\hline
\end{tabular}

atopic dermatitis in 2018, each occurring in only $0.2 \%$ of adults with atopic dermatitis, respectively (Table 2). However, $98.2 \%$ of adults with atopic dermatitis had an atopic dermatitisrelated outpatient office visit, and 91.4\% filled an atopic dermatitisrelated outpatient prescription, with a mean (SD) of 5.5 (5.7) prescriptions per patient on average during 2018. Overall, $77.1 \%$ of adults with atopic dermatitis filled a prescription for topical therapies, and $74.6 \%$ filled a prescription for systemic therapies in
2018. Use of phototherapy for treatment of atopic dermatitis was rare and occurred in $1.5 \%$ of patients.

In 2018, unadjusted mean total allcause health care costs were $\$ 4,979$ higher for adults with atopic dermatitis than controls (Figure 2). This was driven by greater spending on outpatient services (\$7,566 vs $\$ 5,344$, $\mathrm{P}<0.001)$ and outpatient pharmacy claims ( $\$ 4,665$ vs $\$ 1,969, \quad \mathrm{P}<0.001)$. Spending on outpatient services was higher for patients with atopic dermatitis than matched controls in every category, including outpatient office visits $(\$ 1,033$ vs $\$ 540, P<0.001)$ and other outpatient services, including radiology, laboratory, and phototherapy $(\$ 6,023$ vs $\$ 4,359, P<0.001)$. Adults with prevalent atopic dermatitis in 2018 had higher unadjusted direct costs than those with incident atopic dermatitis (Supplementary Table 2, available in online article). For adults with atopic dermatitis, 16.3\% (\$2,381) of all-cause health care spending could be directly attributed to atopic dermatitis-related claims, of which \$384 was from medical claims and $\$ 1,997$ was from outpatient pharmacy claims, of which $72 \%$ was from dupilumab prescription costs.

After adjusting for baseline patient characteristics, total all-cause health care costs in 2018 were $\$ 2,687$ higher for adults with prevalent atopic dermatitis compared with controls (\$13,999 vs $\$ 11,312, \mathrm{P}<0.001)$. By comparison, total all-cause costs were $\$ 363$ higher for adults with incident atopic dermatitis compared with controls $(\$ 11,674$ vs $\$ 11,312, P=0.008$; Supplementary Table 3, available in online article). Compared with controls, adjusted allcause prescription costs were $\$ 5,592$ higher for adults with prevalent atopic dermatitis (\$7,939 vs $\$ 2,347)$ and $\$ 1,405$ higher for adults with incident atopic dermatitis (\$3,751 vs \$2,347). The full multivariable results can be found in Supplementary Table 3.

Absenteeism data were available for $2.3 \%$ of patients with atopic dermatitis and $2.6 \%$ of controls in the 2018 cohort; short-term disability data were available for $15.8 \%$ of adults with atopic dermatitis and $15.4 \%$ of controls; and workers' compensation data were available for $10.3 \%$ of patients with atopic dermatitis and $10.4 \%$ of controls (Table 3). Use of workers' compensation was similar between patients with atopic dermatitis and 


\section{TABLE 2 All-Cause and Atopic Dermatitis-Related Health Care Utilization Among Adult Patients in the 2018 Cohort}

\begin{tabular}{|c|c|c|c|c|}
\hline & \multicolumn{2}{|c|}{ All cause } & \multicolumn{2}{|c|}{$A D$ related ${ }^{a}$} \\
\hline & $\begin{array}{l}\text { Adult AD cohort } \\
(n=31,164)\end{array}$ & $\begin{array}{l}\text { Adult control cohort } \\
\qquad(n=93,492)\end{array}$ & $\begin{array}{c}\text { Incremental } \\
\text { difference }\end{array}$ & $\begin{array}{c}\text { Adult AD cohort } \\
(n=31,164)\end{array}$ \\
\hline \multicolumn{5}{|l|}{ Inpatient admissions } \\
\hline Patients with an admission, $\mathrm{n}(\%)$ & $1,680 \quad(5.4)$ & $4,996 \quad(5.3)$ & $0.05 \%$ & $(0.2)$ \\
\hline Number of admissions, ${ }^{\mathrm{b}}$ mean (SD) & $1.2 \quad(0.7)$ & $1.3 \quad(0.7)$ & -0.02 & $(0.0)$ \\
\hline Length of stay in days, ${ }^{c}$ mean (SD) & $3.8 \quad(4.0)$ & $3.8 \quad(4.8)$ & -0.05 & $5.3 \quad(5.2)$ \\
\hline \multicolumn{5}{|l|}{ Outpatient services } \\
\hline Patients with an ED visit, $\mathrm{n}(\%)$ & $6,664 \quad(21.4)$ & $16,462 \quad(17.6)^{\mathrm{e}}$ & $3.8 \%$ & $(0.2)$ \\
\hline Number of ED visits, ${ }^{\text {d }}$ mean (SD) & $0.4 \quad(0.9)$ & $0.3(0.8)^{\mathrm{e}}$ & 0.1 & $0.0 \quad(0.1)$ \\
\hline Patients with an outpatient office visit, n (\%) & $31,124 \quad(99.9)$ & $78,740 \quad(84.2)^{\mathrm{e}}$ & $15.7 \%$ & $30,600 \quad(98.2)$ \\
\hline Number of outpatient office visits, ${ }^{d}$ mean (SD) & $9.1 \quad(7.5)$ & $4.8 \quad(5.7)^{\mathrm{e}}$ & 4.3 & $1.6 \quad(1.4)$ \\
\hline Patients with other outpatient services, n (\%) & $29,998 \quad(96.3)$ & $79,141 \quad(84.7)^{\mathrm{e}}$ & $11.6 \%$ & $12,320 \quad(39.5)$ \\
\hline Number of other outpatient services, ${ }^{\text {d }}$ mean (SD) & $15.4(19.1)$ & $9.2(14.6)^{e}$ & 6.2 & $0.8 \quad(3.5)$ \\
\hline Patients with a phototherapy service, n (\%) & $608 \quad(2.0)$ & $48 \quad(0.1)^{\mathrm{e}}$ & $1.9 \%$ & $464 \quad(1.5)$ \\
\hline Number of phototherapy services ${ }^{d}$, mean (SD) & $0.4 \quad(4.1)$ & $0.01 \quad(0.7)^{\mathrm{e}}$ & 0.4 & $0.2 \quad(3.2)$ \\
\hline \multicolumn{5}{|l|}{ Outpatient pharmacy services } \\
\hline Patients with an outpatient prescription, $\mathrm{n}(\%)$ & $30,261 \quad(97.1)$ & $75,840 \quad(81.1)^{\mathrm{e}}$ & $16.0 \%$ & $28,479 \quad(91.4)$ \\
\hline Number of prescriptions, ${ }^{d}$ mean (SD) & $21.3(21.7)$ & $14.0(18.9)^{\mathrm{e}}$ & $723.6 \%$ & $5.5 \quad(5.7)$ \\
\hline \multicolumn{5}{|c|}{ AD patients with a prescription for AD-related medications, $\mathrm{n}(\%)$} \\
\hline \multicolumn{5}{|l|}{ Systemic medications } \\
\hline Antibiotics & & & & $4,222 \quad(13.5)$ \\
\hline Antihistamines & & & & $4,883 \quad(15.7)$ \\
\hline Antivirals & & & & $4,116 \quad(13.2)$ \\
\hline Oral corticosteroids & & & & $13,424 \quad(43.1)$ \\
\hline Dupilumab & & & & $1,989 \quad(6.4)$ \\
\hline Immunosuppressants & & & & $406 \quad(1.3)$ \\
\hline \multicolumn{5}{|l|}{ Topical medications } \\
\hline Antibiotics & & & & $17,627 \quad(56.6)$ \\
\hline Calcineurin inhibitors & & & & $2,992 \quad(9.6)$ \\
\hline Corticosteroids & & & & $22,138 \quad(71.0)$ \\
\hline PDE-4 inhibitors & & & & $2,402 \quad(7.7)$ \\
\hline
\end{tabular}

${ }^{a} A D$ claims were defined as medical claims with a diagnosis of $A D$ and outpatient pharmacy claims for corticosteroids, antibiotics, calcineurin inhibitors, antivirals, dupilumab, immunosuppressants, or phosphodiesterase-4 inhibitors. A list of generic names of drugs is included in Supplementary Table 1.

${ }^{b}$ Among patients with at least 1 admission.

cPer admission.

${ }^{\mathrm{A}}$ Among all patients.

eP $<0.001, A D$ cohort vs control cohort.

$A D=$ atopic dermatitis.

controls. However, a higher percentage of adults with atopic dermatitis had an absence claim $(80.0 \%$ vs $75.5 \%, P<0.001)$ or a short-term disability claim than controls $(5.9 \%$ vs $4.7 \%$,
$\mathrm{P}<0.001)$. Adults with atopic dermatitis had higher indirect costs due to short-term disability claims than controls (\$360 vs $\$ 276, P=0.01$ ). 


\section{FIGURE 2 All-Cause and Atopic Dermatitis-Related Direct Health Care Costs Among Adult Patients in the 2018 Cohort}

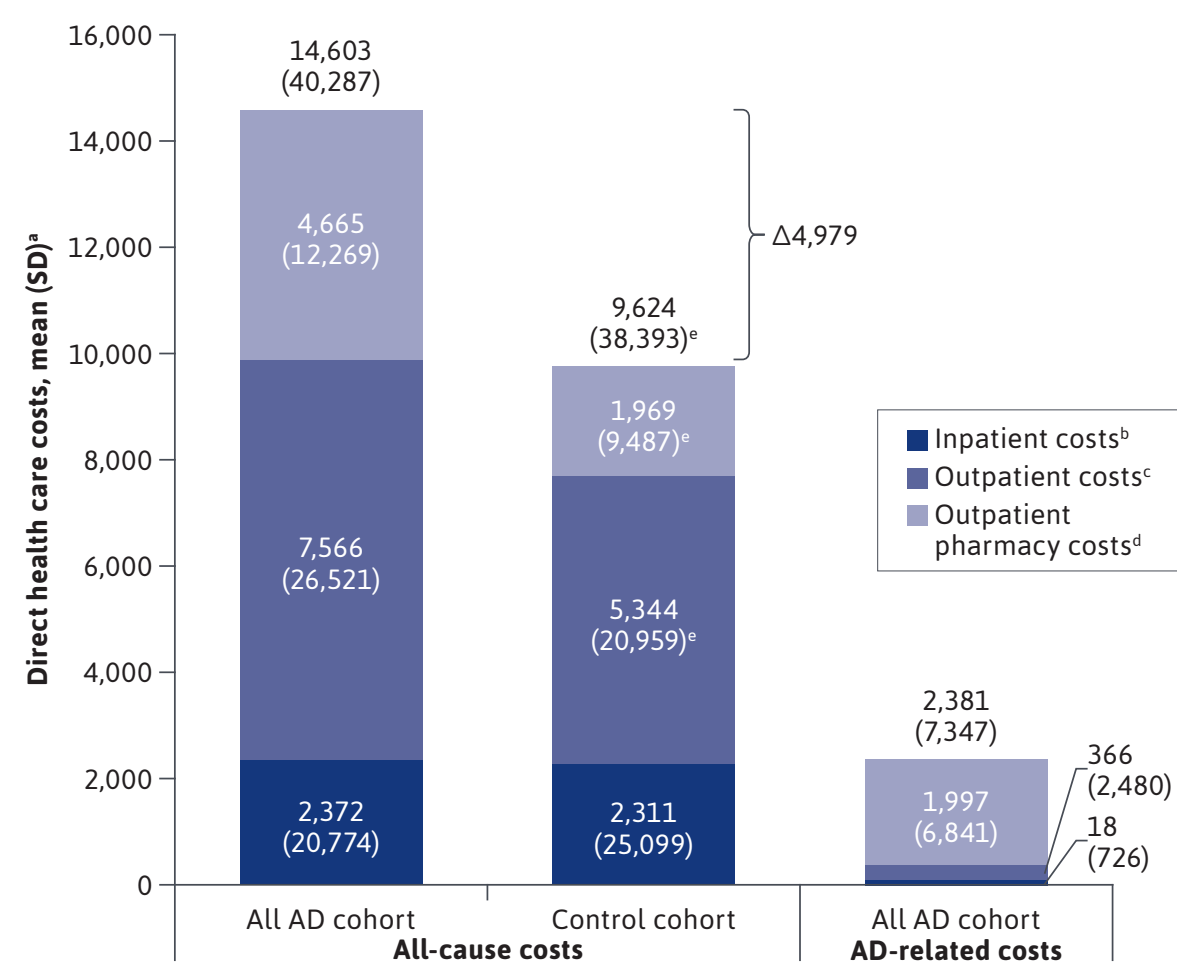

${ }^{a}$ Costs are in 2018 US dollars.

'Inpatient costs included hospitalizations.

'Outpatient costs included emergency department visits, outpatient office visits, and other outpatient services such as phototherapy service and office-administered medications.

dOutpatient pharmacy costs included all prescriptions filled in an outpatient pharmacy setting.

e $P<0.001$ compared with AD cohort.

$A D=$ atopic dermatitis.

\section{SECONDARY ANALYSIS}

Similar results were found when the analysis was repeated for adults with a qualifying atopic dermatitis diagnosis in 2017 or in 2016. Adults with atopic dermatitis in 2017 or 2016 had greater unadjusted all-cause health care resource utilization than matched controls across all categories, and differences in total direct costs between atopic dermatitis patients and controls had been rising over time: $\$ 4,031$ in 2016 and $\$ 4,646$ in 2017, compared with $\$ 4,979$ in 2018 (Supplementary Table 2). For patients with atopic dermatitis in 2017 or 2016, 10.6\% $(\$ 1,466)$ or $7.1 \%$ (\$938), respectively, could be directly attributed to atopic dermatitis-related claims.

After adjusting for baseline differences, all-cause direct costs were significantly higher for patients with incident or prevalent atopic dermatitis than controls in 2017 but not in 2016 (Supplementary Table 3). Work-loss findings followed similar trends as 2018, although not all findings rose to the level of statistical significance (Supplementary Table 4, available in online article).
Weather variables were examined in the 2016 and 2017 cohorts. During the spring and summer seasons, the average temperature and average humidity measures were comparable between atopic dermatitis patients and controls. Of the 3 pollen indices (grass, ragweed, and tree), tree pollen, reported in person-days, was highest during the spring (MarchMay) of 2016 and 2017, for both atopic dermatitis cases and controls, with approximately a quarter of the days categorized as having high/very high pollen counts. In the multivariable models, pollen index, average temperature, and average humidity were not a large driver of cost differences between atopic dermatitis patients and controls (Supplementary Table 3).

\section{Discussion}

The findings of this study support the growing understanding that atopic dermatitis is not solely a childhood illness and presents a substantial economic burden in adulthood. We report a 2018 prevalence of atopic dermatitis of $0.33 \%$ among adults. This is substantially lower than survey estimates of $3.2 \%-10.2 \%,{ }^{3}$ in which patients responded to the question "During the past 12 months, have you had dermatitis, eczema, or any other red, inflamed skin rash?" with or without comorbid asthma or hay fever. This large discrepancy is likely due to 3 primary factors. First, claims data only capture patients who received medical care for atopic dermatitis and likely represent patients with more severe disease. Second, survey data rely on patient memory and an accurate understanding of their diagnosis. Third, patients whose clinician used a more general code such as L30.9 for unspecified dermatitis would not have been captured by our analysis.

Adults with atopic dermatitis had more comorbidities, greater utilization 


\section{TABLE 3}

Indirect Cost of Atopic Dermatitis

\begin{tabular}{|c|c|c|c|c|c|c|}
\hline \multirow[b]{2}{*}{ Patients with absence eligibility, $n$ (\%) } & \multicolumn{2}{|c|}{$\begin{array}{l}\text { Adult AD cohort } \\
(n=31,164)\end{array}$} & \multicolumn{2}{|c|}{$\begin{array}{l}\text { Adult control cohort } \\
\qquad(n=93,492)\end{array}$} & \multirow{2}{*}{$\begin{array}{c}\text { Incremental } \\
\text { difference }\end{array}$} & \multirow{2}{*}{$\begin{array}{c}\text { P value } \\
0.02\end{array}$} \\
\hline & 726 & $(2.3)$ & 2,407 & $(2.6)$ & & \\
\hline Patients with an absence claim, n (\%) & 581 & $(80.0)$ & 1,817 & $(75.5)$ & $4.5 \%$ & 0.01 \\
\hline Indirect costs, mean (SD) & $\$ 6,323$ & $(\$ 4,226)$ & $\$ 6,037$ & $(\$ 4,681)$ & $\$ 286$ & 0.14 \\
\hline Patients with short-term disability eligibility, n (\%) & 4,936 & $(15.8)$ & 14,491 & $(15.4)$ & $0.4 \%$ & 0.07 \\
\hline Patients with a short-term disability claim, n (\%) & 291 & $(5.9)$ & 672 & $(4.7)$ & $1.2 \%$ & $<0.001$ \\
\hline Indirect costs, mean (SD) & $\$ 360$ & $(\$ 2,266)$ & $\$ 276$ & $(\$ 1,860)$ & $\$ 84$ & 0.01 \\
\hline Patients with workers' compensation eligibility, n (\%) & 3,201 & $(10.3)$ & 9,766 & $(10.4)$ & $-0.1 \%$ & 0.39 \\
\hline Patients with a workers' compensation claim, n (\%) & 26 & $(0.8)$ & 68 & $(0.7)$ & $0.1 \%$ & 0.5 \\
\hline Indirect costs, mean (SD) & $\$ 104$ & $(\$ 1,670)$ & $\$ 89$ & $(\$ 1,472)$ & $\$ 15$ & 0.63 \\
\hline
\end{tabular}

Note: Costs are in 2018 US dollars.

$A D=$ atopic dermatitis.

of health care services, higher direct health care costs, and higher utilization of absence and short-term disability benefits than matched controls. We found that the adjusted incremental direct health care burden of atopic dermatitis has been increasing over time from nonsignificant in 2016, to $\$ 454$ for prevalent atopic dermatitis and $\$ 316$ for incident atopic dermatitis in 2017, and up to $\$ 2,687$ for prevalent atopic dermatitis and $\$ 363$ for patients with incident atopic dermatitis in 2018. There are additional therapies being studied for atopic dermatitis, including JAK inhibitors and other new biologics (eg, interleukin-13 and interleukin-31), which are likely to be approved by the US Food and Drug Administration. These therapies will have an effect on higher health care costs.

Environmental factors, including climate, are thought to play a role in disease activity and flares..$^{16-18}$ In the United States, office visits and hospitalization rates for atopic dermatitis peak in the spring/summer and are higher in the South compared with other regions. ${ }^{10,19}$ However, data relating to climate factors and atopic dermatitis are conflicting, with heat, humidity, and ultraviolet exposure associated with a decreased odds of developing atopic dermatitis and an increased odds of poorly controlled atopic dermatitis. . $^{1720}$ Results of this study adjusted for potential differences in weather elements between atopic dermatitis patients and controls.

The results of this study are similar to previous studies of the direct health care costs of adult atopic dermatitis. ${ }^{8,21}$ In a study spanning 2010-2015, the adjusted incremental cost of adult atopic dermatitis was $\$ 3,274$ for patients with commercial insurance, $\$ 3,200$ for those with Medicare supplemental insurance, and $\$ 9,054$ for those with Medi-Cal insurance. ${ }^{8}$ Similarly, an analysis of MarketScan data from 2013 reported that the adjusted incremental cost of adult atopic dermatitis was $\$ 3,302 .{ }^{21}$ Outpatient costs were the primary driver, comprising $49 \%-57 \%$ of all costs depending on insurer and study.

\section{LIMITATIONS}

There are several limitations to this study. First, claims data are collected for administrative purposes and are subject to data entry errors, miscoding, and undercoding. Mild cases of atopic dermatitis may not have been captured in claims, so our control population may have contained patients with mild cases of atopic dermatitis, and our prevalence calculation may have underestimated the true prevalence, since we only captured patients who sought health care.

Second, claims data only capture prescription medications and do not capture use and spending on nonprescription medications, such as humectants, nonprescription topical steroids, and antipruritic medications, which are known drivers of out-of-pocket expenses for atopic dermatitis. ${ }^{5}$

Third, the analyses only captured investigated prescription medications and did not capture any information for noninvestigated prescriptions, including other atopic dermatitis treatments not in the investigated classes, such as methotrexate. Additionally, investigated prescriptions may have been used for more than 1 disease or may not have been linked to atopic dermatitis.

Fourth, the reason for work-loss claims was not captured, so individual claims cannot be specifically linked to atopic dermatitis. Fifth, patients with atopic dermatitis were not mutually exclusive in each study calendar year, 
since a prevalent atopic dermatitis population was examined.

Sixth, patients categorized as having incident atopic dermatitis may have had a diagnosis of atopic dermatitis before the 24-month baseline period and may not have been true incident cases. Also, claims related to atopic dermatitis were based on a claim with an atopic dermatitis diagnosis in any position, so it is possible that some claims may have been inaccurately identified as such.

Finally, this study used data from patients with commercial or Medicare supplemental insurance and may not be applicable to patients with other insurance or without insurance.

\section{Conclusions}

Adults with a diagnosis of atopic dermatitis had significantly greater health care resource utilization, direct costs, and indirect costs compared with matched controls during calendar years 2016, 2017, and 2018. It is important to recognize that the burden of atopic dermatitis goes beyond skin disease and might include the effect on quality of life related to itch, sleep disturbances, and related comorbidities, such as anxiety and depression.

\section{DISCLOSURES}

This study was funded by Eli Lilly and Company. Employees of Eli Lilly were involved in the planning, execution, and interpretation of the study. Pierce is employed by Eli Lilly and Company. Boytsov and Goldblum were employed by Eli Lilly and Company Health at the time this research was conducted. Manjelievskaia and Brouillette are employed by IBM Watson Health, which received funding from Eli Lilly and Company to conduct this study. Bonafede and Onyekwere were employed at IBM Watson Health at the time this research was conducted.

\section{ACKNOWLEDGMENTS}

Medical writing services were provided by Jessamine Winer-Jones, PhD, of IBM Watson Health. Programming services were provided by Cyndi R. Wallin, and statistical modeling services were provided by Nicole M. Zimmerman, both of IBM Watson Health. These services were paid for by Eli Lilly and Company.

\section{REFERENCES}

1. Weidinger S, Novak N. Atopic dermatitis. Lancet. 2016;387(10023):1109-22.

2. Eichenfield LF, Tom WL, Chamlin SL, et al. Guidelines of care for the management of atopic dermatitis: section 1. Diagnosis and assessment of atopic dermatitis. J Am Acad Dermatol. 2014;70(2):338-51.

3. Silverberg JI, Hanifin JM. Adult eczema prevalence and associations with asthma and other health and demographic factors: a US population-based study. J Allergy Clin Immunol. 2013;132(5):1132-38.

4. Drucker AM, Wang AR, Li W-Q, Sevetson E, Block JK, Qureshi AA. The burden of atopic dermatitis: summary of a report for the National Eczema Association. J Invest Dermatol. 2017;137(1):26-30.

5 . Fivenson D. The effect of atopic dermatitis on total burden of illness and quality of life on adults and children in a large managed care organization. J Manag Care Pharm. 2002;8(5):333-42. doi: 10.18553/ jmcp.2002.8.5.333

6. Silverberg JI. Health care utilization, patient costs, and access to care in US adults with eczema: a population-based study. JAMA Dermatol. 2015;151(7):743-52.

7. Holm E, Esmann S, Jemec G. The handicap caused by atopic dermatitis sick leave and job avoidance. J Eur Acad Dermatol Venereol. 2006;20(3):255-59.

8. Shrestha S, Miao R, Wang L, Chao J, Yuce H, Wei W. Burden of atopic dermatitis in the United States: analysis of healthcare claims data in the commercial, Medicare, and Medi-Cal databases. Adv Ther 2017;34(8):1989-2006.
9. Bickers DR, Lim HW, Margolis D, et al. The burden of skin diseases: 2004: a joint project of the American Academy of Dermatology Association and the Society for Investigative Dermatology. J Am Acad Dermatol. 2006;55(3):490-500.

10. Narla S, Hsu DY, Thyssen JP, Silverberg JI. Inpatient financial burden of atopic dermatitis in the United States. J Invest Dermatol. 2017;137(7):1461-67.

11. Eichenfield LF, Ahluwalia J, Waldman A, et al. Current guidelines for the evaluation and management of atopic dermatitis: a comparison of the Joint Task Force Practice Parameter and American Academy of Dermatology guidelines. J Allergy Clin Immunol. 2017;139(4S):S49-S57.

12. Deyo RA, Cherkin DC, Ciol MA. Adapting a clinical comorbidity index for use with ICD-9-CM administrative databases. J Clin Epidemiol. 1992;45(6):613-19.

13. US Bureau of Labor Statistics. Consumer Price Index. Accessed October 1, 2020. https://www.bls.gov/cpi/home. $\underline{\mathrm{htm}}$

14. Simpson H. Short-term disability benefits. Compensation and Working Conditions (US Bureau of Labor Statistics). Summer 1997. Accessed August 3, 2021. https://www.bls.gov/opub/mlr/cwc/ short-term-disability-benefits.pdf

15. Graubard BI, Korn EL. Predictive margins with survey data. Biometrics. 1999;55(2):652-59.

16. Peng W, Novak N. Pathogenesis of atopic dermatitis. Clin Exp Allergy. 2015;45(3):566-74.

17. Silverberg JI, Hanifin J, Simpson EL. Climatic factors are associated with childhood eczema prevalence in the United States. J Invest Dermatol. 2013;133(7):1752-59.

18. Kantor R, Silverberg JI. Environmental risk factors and their role in the management of atopic dermatitis. Expert Rev Clin Immunol. 2017;13(1):15-26.

19. Fleischer AB Jr. Atopic dermatitis: the relationship to temperature and seasonality in the United States. Int J Dermatol. 2019;58(4):465-71. 
20. Sargen MR, Hoffstad O, Margolis DJ. Warm, humid, and high sun exposure climates are associated with poorly controlled eczema: PEER (Pediatric Eczema Elective Registry) cohort, 2004-2012.

J Invest Dermatol. 2014;134(1):51-57.
21. Drucker AM, Qureshi AA, Amand C, et al. Health care resource utilization and costs among adults with atopic dermatitis in the United States: a claims-based analysis. J Allergy Clin Immunol Pract. 2018;6(4):1342-48. 